\title{
Response Regarding Existential Issues in Sexual Medicine: The Relation Between Death Anxiety and Hypersexuality
}

The recent article published by Dr Watter, "Existential Issues in Sexual Medicine: The Relation Between Death Anxiety and Hypersexuality," ${ }^{\prime 1}$ deals with an interesting issue: the unique relation between death and sexuality.

Existential psychotherapy is the main perspective on which the article is focused, as can be seen in Dr Watter's choice of words, "on concerns rooted in the individual's existence." However, the original background of the relation between death and sexuality derives definitively from psychoanalysis and the theoretical work of Sigmund Freud, ${ }^{2}$ as incidentally affirmed by Dr Watter when writing that "Freud, too, recognized the powerful connection between the sex drive (Eros) and the death instinct (Thanatos)." Moreover, we have reason to believe, although with some critical positions, that a large part of post-Freudian thought is based on the contraposition between Eros and Thanatos. In this regard, hypersexual individuals try to antagonize depressive states and death anxiety with a life instinct through sexual activities, although in a dysregulated way. Therefore, hypersexual behaviors can be bona fide considered a defensive behavior against death anxiety.

Although Dr Watter gives new cues of research on hypersexuality, he only partly cites the psychoanalytic perspective that is the angular stone on which his theory and the topic of the article is built on.

Psychoanalysis originates from philosophy and from Darwinian evolutionism ${ }^{3}$ and the theory of sexuality with subsequent revisions ${ }^{2}$ has strong evolutionary and biological matrices: the sex drive against the death drive in favor of life conservation. From this Freudian and Darwinian perspective, hypersexual behavior could represent an extreme strategy to cope with the profound sense of death. In this regard, Dr Watter fails to adequately distinguish among fear of death, death anxiety, and the death instinct. ${ }^{2}$ This is a crucial aspect to describe the phenomenology of hypersexuality from an intrapsychic point of view.

Hypersexual patients resist great internal suffering with a high frequency of sexual activities. This could be due in part to latent forms of severe depression, anxiety, or other psychopathologic syndromes. Moreover, it is controversial when hypersexuality can be considered a disease and its diagnostic process still needs solid theoretical bases. ${ }^{4}$ In consequence, the treatment of a hypersexual patient proves very problematic.

A final question raised in the article is whether clinicians should directly act on hypersexual behavior. We only partly agree with Dr Watters' suggestion. We believe that sexual physicians, psychiatrists, psychotherapists, and sexologists should not confine themselves to the treatment of hypersexual behavior but, when and where possible, should include its intrapsychic and interpersonal roots. ${ }^{2}$ Therefore, a structural-developmental psychodynamic approach should be considered rather than a symptomatic one.

To date, very few articles and mostly case reports and singlegroup studies, particularly regarding cognitive behavioral psychotherapies and pharmacologic treatments, have investigated the effectiveness and efficacy of therapies for hypersexuality. ${ }^{5} \mathrm{We}$ maintain that a psychotherapeutic approach, substantiated by empirical research, should be a major goal, and we invite existential psychotherapists and psychoanalysts to experimentally verify their therapies for hypersexual patients.

Giacomo Ciocca ${ }^{\top}$, Erika Limoncin', Vittorio Lingiardi ${ }^{2}$, Andrea Burri ${ }^{3}$, and Emmanuele A. Jannini, ${ }^{1, *}$ 'ENDOSEX, Department of Systems Medicine, University of Rome Tor Vergata, Rome, Italy

${ }^{2}$ Department of Dynamic and Clinical Psychology, Sapienza University of Rome, Rome, Italy

${ }^{3}$ European Institute for Sexual Health, Hamburg, Germany

Corresponding Author: Emmanuele A. Jannini, MD, Chair of Endocrinology and Medical Sexology (ENDOSEX), Department of Systems Medicine, University of Rome Tor Vergata, Via Montpellier 1, Roma 00131, Italy. Tel: +39-0862-433530; Fax: +39-0862-433523; E-mail: eajannini@gmail.com

Conflicts of Interest: The authors declare no conflict of interest. Funding: None.

http://dx.doi.org/10.1016/j.sxmr.2018.02.002

\section{STATEMENT OF AUTHORSHIP}

\section{Category 1}

(a) Conception and Design

Giacomo Ciocca; Erika Limoncin; Vittorio Lingiardi; Andrea Burri; Emmanuele A. Jannini

(b) Acquisition of Data

Giacomo Ciocca; Erika Limoncin; Vittorio Lingiardi; Andrea Burri; Emmanuele A. Jannini

(c) Analysis and Interpretation of Data

Giacomo Ciocca; Erika Limoncin; Vittorio Lingiardi; Andrea Burri; Emmanuele A. Jannini

\section{Category 2}

(a) Drafting the Article

Giacomo Ciocca; Erika Limoncin; Vittorio Lingiardi; Andrea Burri; Emmanuele A. Jannini

(b) Revising It for Intellectual Content 
Giacomo Ciocca; Erika Limoncin; Vittorio Lingiardi; Andrea Burri; Emmanuele A. Jannini

\section{Category 3}

(a) Final Approval of the Completed Article Giacomo Ciocca; Erika Limoncin; Vittorio Lingiardi; Andrea Burri; Emmanuele A. Jannini

\section{REFERENCES}

1. Watter DN. Existential issues in sexual medicine: the relation between death anxiety and hypersexuality. Sex Med Rev 2018;6:3-10.
2. Freud S. Beyond the pleasure principle. London, Vienna: International Psycho-Analytical; 1922. New York: Bartleby.com; 2010 [reprint].

3. Ritvo LB. The impact of Darwin on Freud. Psychoanal Q 1974;43:177-92.

4. Lingiardi $V$, McWilliams N. The psychodynamic diagnostic manual. 2nd edition. World Psychiatry 2015;14:237-9.

5. Hook JN, Reid RC, Penberthy JK, et al. Methodological review of treatments for nonparaphilic hypersexual behavior. J Sex Marital Ther 2014;40:294-308.

\section{Response and Rebuttal to "Existential Issues in Sexual Medicine: The Relation Between Death Anxiety and Hypersexuality"}

Let me begin by expressing my gratitude to Dr Ciocca et $\mathrm{al}^{1}$ regarding my article, "Existential Issues in Sexual Medicine: The Relation Between Death Anxiety and Hypersexuality." It is most gratifying to know that the article has been read and found worthy of commentary. My primary hope in submitting this article was that it would be a catalyst for discussion and analysis of the complicated area of hypersexuality, a topic that has created quite a division in sexual medicine.

There are several points made by Ciocca et al that I am in complete agreement with, and I believe such agreement is reflected in my article. For example, they state that hypersexuality could result from many underlying conditions, not only the terror of death. As mentioned on page 9 of my article, I describe death anxiety as $a$ trigger for hypersexual behavior, not the only trigger. ${ }^{2}$ Later in the letter, Ciocca et al raise the question of whether clinicians should directly act on the hypersexual behavior and suggest that a structural-developmental psychodynamic approach should be considered rather than a symptomatic one. I would point to page 9 in the article under the section titled Treatment and my comment, “... existential psychotherapy focuses less on the presenting symptom(s) per se and more on the meaning the symptom(s) has for the individual." In addition, on page $4 \mathrm{I}$ make the argument that a focus on the symptom of hypersexuality would likely lead only to a temporary amelioration of the problem because crucial psychodynamic factors that are likely to be represented in the expression of the hypersexual behavior will remain unaddressed.

However, there are some areas of disagreement that I would like to address and clarify. Dr Ciocca et al suggest that I do not do justice to the contributions of Freud in the notion that hypersexual behavior can be considered a defensive behavior in combating death anxiety. Although I greatly respect, admire, and appreciate the work of Freud, the existential approach to psychotherapy has several nuanced differences that separate it from Freudian theory. Freud, in his work, actually discouraged patients from talking about their fears of death, because he viewed anxiety about death as an unconscious representation of castration or abandonment. ${ }^{3}$ In Yalom's discussion of Breuer and Freud's groundbreaking work, Studies on Hysteria, ${ }^{5}$ he noted, "It is a fascinating work and merits attention for it illustrates strikingly a selective inattention to death, and it laid the foundation for the exclusion of death from the entire field of dynamic therapy which it spawned" [p. 59]. Therefore, my cursory mention of Freud in my article was not to give short shrift to his genius or his work, but rather because Freud's conceptions of death are not necessarily related to the anxiety or terror of death itself and are not directed toward an understanding of the existential meaning of our existence. As such, Freud's conceptualization of the role of death and its place in treatment is not consistent with the existential approach to psychotherapy.

Again, let me express my thanks and appreciation to Dr Ciocca et al for sharing their thoughts about my article. We have much to learn about approaches to the treatment of sexual problems, and I welcome the collaboration with those whose views regarding treatment might differ from mine.

Daniel N. Watter, EdD*

Morris Psychological Group, PA, Parsippany, NJ, USA

Corresponding Author: Daniel N. Watter, EdD, Morris Psychological Group, PA, 50 Cherry Hill Road, Suite 305, Parsippany, NJ 07054, USA. Tel: 973-257-9000, ext 202; Fax: 973-257-0506; E-mail: drwatter@morrispsych.com

Conflicts of Interest: The author has no conflict of interest to report.

Funding: None.

http://dx.doi.org/10.1016/j.sxmr.2018.02.001

\section{STATEMENT OF AUTHORSHIP}

\section{Category 1}

(a) Conception and Design

Daniel N. Watter 